\title{
Ciências da atividade física: algumas perguntas
}

\author{
György Miklós Böhm*
}

Dois amigos convidaram-me para que desse uma aula. À menção da platéia de pessoas interessadas em atividade física e que gostariam de ouvir algo relacionado de como é que se faz Ciência, eu imediatamente aceitei, diria sem nenhuma hesitação, por um ato reflexo. O responsável por esta imprudência certamente foi o meu tendão esquerdo dos gêmeos, lá onde se incere na tuberosidade do calcâneo, ou seja, o tendão de Aquiles esquerdo. Trata-se de uma parte do meu corpo cronicamente inflamada e que dialoga comigo a toda hora. Existem outras regiões incômodas, metatarso do pé direito, joelho direito, coluna lombar, próstata - isto quando não estou com gota ou tromboflebite ! - contudo, o tendão é o mais eloqüente e antes que pudesse pensar, refletir seriamente, ele adiantou-se e respondeu positivamente ao convite. Depois que me despedi dos colegas, ao sentar junto à mesa de trabalho, o tendão deu uma pequena ferroada dizendo: "está vendo ? agora agüenta !"

A palestra começou com uma curta introdução, em que abordei alguns aspectos gerais da Ciência, e, depois, passei à parte central do tema, cujo conteúdo transcrevo:

"Entretanto, o mais importante para aqueles que desejam pesquisar ou se aprimorar no campo da Ciência é entrar no jogo, talvez o jogo mais interessante do mundo que é a Pesquisa. Praticar, treinar, meter a mão na massa é isto o que importa. Ler muito sobre a Ciência ou sobre os métodos de pesquisa só poderá levar a uma certa erudição e nada mais. Aos que se iniciam, recomendo que achem um orientador, um bom orientador. Penso que isto é ponto pacífico, pois o paralelo com as atividades esportivas é evidente. E como é que se reconhece um bom orientador? Ele deverá ter, pelo menos, duas qualidades essenciais: ter uma linha de pesquisa ativa e gostar de educar. Entre estas duas coisas, o mais fácil de reconhecer é a linha de pesquisa ativa: basta ler o currículo do orientador e verificar se os seus trabalhos aparecem em boas revistas científicas e se têm uma coerência entre os mesmos. A questão, se gosta ou não de educar, dá para investigar junto aos seus discípulos, exceto quando se trata de um orientador jóvem, iniciante, e que ainda não tenha orientandos. Talvez tenha uma dica interessante para vocês: procurem ver, ou melhor, sentir se o orientador ensina ou educa. Um abismo separa estas duas atitudes. Aquele que gosta ensinar é homem de platéia, é conferencista, é transmissor de seus conhecimentos, semeador de habilidades e técnicas. Jamais se cansa de explicar sua especialidade e de demostrá-la. Entretanto, o ensinador, 
perdoem o neologismo, está apenas preocupado com o seu próprio desempenho. O educador vai além: mais do que com o ensino, está preocupado com o aprendizado. O educador está interessado nos resultados do ensino, ou seja, vive para o aprendizado daqueles que educa. Deu para entender?

É extremamente importante escolher bem o problema que se vai pesquisar. Gosto de citar o prêmio Nobel húngaro-americano, Von Békésy, que sublinha a conveniência de analisar o tipo de questão que se deseja abordar e avaliar devidamente suas peculiaridades. Desta forma há:

1. Problemas Clássicos, que já mereceram muita atenção e grandes esforços mas são de difícil solução;

2. Problemas Prematuros, que são de difícil formulação ou, ainda, além dos meios disponíveis de investigação;

3. Problemas Estimulantes, que conduzem à reconsideração de princípios estabelecidos e podem abrir novas áreas para explorar;

4. Pseudo-problemas, que são aqueles conseqüientes a diferentes definições ou métodos e, portanto, não existem;

5. Problemas Estatísticos, que geralmente são apenas uma pesquisa de possibilidades;

6. Problemas Sem Importância, que são muito fáceis de formular e igualmente fáceis de resolver e, finalmente,

7. Problemas Embaraçosos, que normalmente aparecem em encontros científicos ou discussões e poucas vezes servem para qualquer coisa de útil.

A escolha de um problema... eis a atividade mais importante do pesquisador. E para escolher, tem que ter problemas. Para ter problemas em Ciência, é preciso conhecer e pensar. Só o conhecimento não basta; quanias vezes não encontramos pessoas que são poços inesgotáveis de informações, porém são incapazes de formularem perguntas ? Quantas vezes crianças, ainda ignorantes, não nos surpreendem com as suas curiosidades ? Na adolescência muitas vezes sofremos traumatismos e refreamos nossas curiosidades, a fim de não pareceremos idiotas, deixamos de externar as nossas dúvidas e, com o passar dos anos, tornamo-nos adultos que perderam a curiosidade e não sabem mais fazer perguntas.

Permitam que traga de volta a minha incerção tendinosa no calcâneo esquerdo, que chamarei doravante coloquialmente de Aquiles. Apesar dos remédios que tomo, Aquiles doi e se faz presente. Eu convivo relativamente bem com o sofrimento físico e tenho as minhas idéias sobre a dor mas que não cabem nesta palestra. É suficiente dizer que ouso sugerir aos colegas fisioterapéutas e médicos que, pelo menos, além de acabar com as dores, procurem que seus pacientes convivam melhor com elas. A dor tem um significado profundo e subjetivo, como se fosse um grande mestre pessoal, e lucra-se muito em entender algumas de suas mensagens. Certamente, ela permite entender melhor a linguagem do corpo.

Linguagem do corpo. Cheguei aonde queria e, agora, tentarei desenvolver um pensamento e dizer a vocês quais seriam as primeiras perguntas que eu faria relacionadas à atividade física, em outras palavras, o que é que eu pesquisaria. Faço isto absolutamente consciente da minha enorme vantagem de ser ignorante nesta área e aqueles que se dedicam à educação do corpo poderão achar este exercício de levantar questões para pesquisa, ridículo. Por outro lado, sei por experiência própria que muitas vezes uma pessoa estranha às nossas linhas de pesquisa pode contribuir com o inesperado, com uma surpresa agradável, com um enfoque que o pesquisador envolvido em seu trabalho jamais imagina, justamente por estar comprometido com uma linha de pensamento que o impede de enxergar outros caminhos.

Há uma dissociação entre corpo e mente que é clássico. São dois mundos diferentes e interligados. Os dois mundos merecem ser descobertos. E fazemos muito pouco para explorá-los, para conhecê-los. Creio não estar equivocado, se afirmar que o corpo merece menos atenção do que a mente. A mente é a sede das idéias e elas têm uma unidade básica que são os ideogramas, expressas com palavras, contudo nem sempre. Uma criança que nasce surda é, também, muda em conseqüência da deprivação da audição e, por certo, não usa vocábulos, porém possui seu arquivo de ideogramas desenvolvido a partir de impulsos criados pelos sentidos que lhe restam.

Pois bem, se os ideogramas são os elementos básicos da linguagem da mente, quais são os elementos básicos da linguagem do corpo ? Poderia arriscar que são as sensações mas sinto-me em um terreno mais pantanoso do que com a mente. A palavra sensação parece-me grande de mais, gostaria que fosse decomposta em seus unidades menores. Um exemplo extremo, talvez ilumine minha dúvida. Imaginemos dois grandes artistas: Luciano Pavarotti e Xavier Soto Mayor. Certamente, ambos devem ter uma enorme intimidade com seus corpos, ou seja, o cantor italiano com seu aparelho de fonação e o atleta cubano com seus membros inferiores. Entretanto, fico perguntando: como será a comunicação da laringe, faringe, cavidades de ressonância e dos outros componentes da emissão vocal ? Não sei, porém instintivamente creio que é bem diferente dos modos de comunicação das articulações e dos músculos das pernas. 
Sempre gostei da voz humana e, na música, é o meu instrumento preferido. Deste modo, nas horas de lazer interajo muito com o canto. (Dos outros, quero ser bem claro para desfazer qualquer dúvida: eu não sei cantar.) Pois bem, existe um livro famoso em que um cantor aposentado, Jerome Hines, entrevista os maiores expoentes do mundo da arte lírica e lhes coloca a questão: como é que você canta ? O que ele quer saber é a parte física: respiração, laringe, ressoadores etc... O resultado é um espanto: estas pessoas ilustres que estudaram durante quatro a oito anos em conservatórios, aprimoraram-se na vida toda e chegaram à excelência em sua arte, parecem não ter a menor idéia de como é que cantam. Transmitem sensações erráticas e vagas, geralmente desmentidas pelas verificações dos fisiologistas, e, o pior, absolutamente inúteis para um neófito que quisesse iniciar a profissão de cantor. Não sei se é um problema real de desconhecimento, ou dificuldades de traduzir a linguagem do corpo em palavras.

Meus amigos. Penso que o mesmo acontece nos outros ramos da atividade física, em qualquer modalidade desportiva. A comunicação é má por desconhecimento da linguagem do corpo. O aprendizado é obtido por imitação, como entre os animais que são aprendizes muito superiores ao homem, e o educador no mais das vezes não é aquele que mais se destaca naquela determinada atividade física. Se isto que acabei de dizer for verdade, os corolários são importantes. E o que é que disse ? Que os animais aprendem atividades físicas com mais facilidade do que o homem. Se assim for, o desenvolvimento da inteligência dificulta o entendimento da linguagem corporal ou, no mínimo, pouca coisa tem a ver com ela. Quer me parecer que é uma boa área para pesquisar. Para exemplificar: Garrincha, que notoriamente teve uma coordenação neuro-muscular fantástica e uma mente limitada, é uma exceção ou um caso ilustrativo que tem muito a nos ensinar? Afirmei tembém que, geralmente, o melhor cantor ou o melhor ginasta, não é a melhor pessoa para a pedagogia e didática do canto ou da ginástica. Em outras palavras, o melhor desempenho da atividade física e o melhor entendimento da linguagem do corpo, não são paralelos. Outras questões para investigação.

Como disse no início, o corpo e a mente são dissociados mas também estão interligados. A linguagem do corpo, sem dúvida, influencia muitíssimo a mente. O exemplo mais notável é a linguagem do sexo. O eu consciente pode bloqueiar muita coisa e desconhecer a linguagem do tornozelo, dos músculos do dorso, do pulmão e do coração, porém dificilmente a do sexo. Esta é impe- rativa e mais forte do que a linguagem da mente. Não conseguimos deixar de escutá-la, podemos desobedecê-la ou conduzir um diálogo deficiente. A razão pela qual eu lembro a poderosa linguagem do sexo é que me surgiu uma idéia: será que sua linguagem não é a chave ou, pelo menos, uma ferramenta auxiliar, para compreender a linguagem do corpo ? de seus fundamentos? sobretudo das vísceras em geral ? E a mesma pesquisa poderia ser feita em relação a maternidade. Certamente, é um dos grande diálogos da mulher com seu corpo.

Maternidade é feminina e um outro pensamento me ocorre. Será que a vaidade não é um caminho melhor para entender a linguagem do corpo do que a glória ? Penso que as mulheres exploram, conhecem, dialogam mais com os seus corpos do que os homens. Verdade ou mentira? Não sei, por enquanto é apenas uma intuição forte mas é um terreno a pesquisar. Só a metodologia, a técnica necessária à esta pesquisa, dá uma tese de doutoramento! Da mesma forma poderia se pesquisar entre aqueles que praticam a musculação, se são os candidatos a conquistas olímpicas ou os narcisistas, ou seja, se são aqueles que se preocupam com a excelência do desempenho de uma atividade física ou se aqueles que vigiam a estética de seu corpo, que têm melhor e maior familiaridade com seus corpos ?

Certamente, as academias de musculação, as artes marciais, os exercícios físicos para manter o corpo, o ensino de danças, ficaram universalmente populares. É impressionante o número de horas que a televisão dedica a estes programas. Creio que devem contribuir bastante para que a pessoa entenda a linguagem de seus músculos e articulações e podem ser ótimos laboratórios científicos. (Colocaria a minha atenção, em primeiro lugar, na dança.) Por outro lado, as escolas de meditação oriental, sobretudo indiana e, neste momento, estou pensando em ioga, são menos difundidas e, talvez, até em declínio. Estes estabelecimentos ofereciam boas oportunidades para entender a linguagem das vísceras, antes de mais nada do pulmão e do coração. Alguns dos grandes mestres do hinduismo e budismo foram e são capazes a expantosas façanhas como controlar o ritmo cardíaco, a vasomotricidade, o peristaltismo intestinal e outras excentricidades. O interesse deles era, por certo, um aperfeiçoamento espiritual, contudo deixaram provas irrefutáveis de que as linguagens das vísceras eram compreensíveis e a mente poderia estabelelcer um bom diálogo com elas. Penso que a educação física deveria se preocupar também com a parte interna do corpo e, neste sentido, uma pesquisa bem orientada, no sentido de rever o alcance pedagógico e a orienta- 
ção didática da Educação Física no esquema educacional do país, seria oportuna. Afinal das contas, mesmo se ouvir as queixas do corpo na terceira idade é uma atividade interessante e, até, estimulante, é inegável que a linguagem do corpo em desenvolvimento e na sua plenitude deveriam ser ainda mais escutadas. Parece óbvio que a sensibilidade da pessoa para entender o seu corpo deve ser desenvolvida o mais cedo possível e esta sensibilidade poderia ser aguçada com explicações, demonstrações e - aí está minha maior curiosidade - com técnicas mais avançadas que só a investigação científica consegue descortinar.

Eu gostaria de incluir as vísceras neste entendimento. No começo elas são elusivas, trabalham à moda mineira: em silêncio. Mais tarde, principalmente na terceira idade manifestam-se e exigem atenção. $\mathrm{O}$ desconforto e a dor têm vozes que devem ser escutadas e não impensadamente silenciadas com analgésicos. A descoberta da linguagem das vísceras pode ser uma das gratas surpresas dos idosos. Esta área está aberta à pesquisa para todos interessados na qualidade de vida daqueles que pertencem à terceira idade. Por sua vez, os resultados desta investigação poderá abrir caminhos para extender a compreensão da linguagem das vísceras aos jóvens, com evidentes vantagens para a prevenção da saúde.

Não sei se consegui me fazer entender. A pretensão deste monólogo deflagrado por Aquiles foi, apenas, de pensar em voz alta e levantar problemas que permitem fazer perguntas à Natureza. Em outras palavras, um pequeno exercício dos passos iniciais da Ciência.
Uma vez compreendidas as bases da linguagem do corpo, poderá se fazer estudos comparativos com a linguagem da mente. E, como hipótese, eu esperaria que a linguagem do corpo fosse mais subjetiva, inteiramente pessoal, totalmente dependente da vida ou, se quiserem, do funcionamento do corpo. Entretanto, não me surpreenderia se a linguagem do corpo fosse a menos ilusória, quero dizer mais real, se é que existe realidade, do que a linguagem da mente. Assim, a morte seria dialeto da linguagem do corpo e não da mente ou, pelo menos, mais daquela do que desta.

Para terminar, lembro que a Ciência exige recursos materiais. Um exame trivial da Ciência no mundo mostra, inequivocadamente, que a qualidade da Ciência e a excelência dos cientistas estão em relação direta com a riqueza das nações. Em outra oportunidade, já disse que a pobreza limita enormemente o campo científico. Contudo, as questões que acabo de levantar precisa mais observação, reflexão, intuição do que grandes recursos econômicos. Inicialmente, basta comprar chá ou café ou cerveja para longas trocas de idéias em fins de tarde, a fim de refinar ou descartar estas perguntas que acabo de colocar. Permito-me recordar a vocês que o cientista necessita da convivência com pensamentos e idéias que estão na cabeça de seus colegas. Um pesquisador sem o estímulo constante de outros que falem sua linguagem, não progride. Aproveito este gancho e convido a todos para um papo acompanhado de uma cervejinha bem gelada."

Obrigado pela atenção 